\title{
Spectroscopic properties of tetravalent uranium in glasses
}

\author{
K. Binnemans ${ }^{\mathrm{a}, *}$, I. Couwenberg ${ }^{\mathrm{a}}$, H. De Leebeeck ${ }^{\mathrm{a}}$, C. Görller-Walrand ${ }^{\mathrm{a}}$, J.L. Adam ${ }^{\mathrm{b}}$ \\ ${ }^{a}$ K.U. Leuven, Department of Chemistry, Coordination Chemistry Division, Celestijnenlaan 200F, B-3001 Heverlee, Belgium \\ ${ }^{\mathrm{b}}$ Université de Rennes I, Laboratoire des Verres et Céramiques, U.M.R. C.N.R.S. 6512, Campus de Beaulieu, F-35042 Rennes Cedex, France
}

Received 17 October 1998; received in revised form 30 November 1998

\begin{abstract}
The spectroscopic properties of the tetravalent uranium ion $\left(\mathrm{U}^{4+}\right)$ have been investigated in fluoride, fluorophosphate and phosphate glasses. Absorption and magnetic circular dichroism (MCD) spectra were recorded. The energy levels of the $5 \mathrm{f}^{2}$ electronic configuration of $\mathrm{U}^{4+}$ are simulated by a set of free-ion parameters and expressions for the $5 \mathrm{f}^{2}$ wavefunctions are presented. The spectroscopic behaviour of $\mathrm{U}^{4+}$ in glasses is compared with the spectroscopic behaviour of $\mathrm{U}^{4+}$ in other matrices. Special attention is paid to the similarities between the $5 \mathrm{f}^{2}$ electronic configuration of tetravalent uranium and the $4 \mathrm{f}^{2}$ configuration of trivalent praseodymium. (C) 1999 Elsevier Science S.A. All rights reserved.
\end{abstract}

Keywords: Actinides; Uranium; Spectroscopy; MCD; Magnetic circular dichroism; Absorption; Fluoride glasses; Praseodymium

\section{Introduction}

The tetravalent uranium ion $\left(\mathrm{U}^{4+}\right)$ is the most widely studied ion among the tetravalent actinide ions. At first, $\mathrm{U}^{4+}$-compounds are much easier to handle than compounds of the heavier actinides, because of the low radioactivity of the natural uranium isotopes. No noticeable radiation effects are observed in samples containing tetravalent uranium. There are no limitations concerning the sample size. Secondly, the +IV oxidation state of uranium is fairly stable (especially in comparison with the $+\mathrm{III}$ and $+\mathrm{V}$ oxidation states). Thirdly, the $5 \mathrm{f}^{2}$ electronic configuration of $\mathrm{U}^{4+}$ provides enough experimental energy levels so that the ion is suitable for theoretical analysis. An early study of the spectroscopic properties of tetravalent uranium has been published by Conway [1]. He studied the $\mathrm{UV}$ to the far-infrared spectrum of $\mathrm{U}^{4+}$ in $\mathrm{CaF}_{2}$ (200 to $8000 \mathrm{~nm}$ ). Conway assigned the free-ion levels and estimated the intensity of the absorption bands. Cohen and Carnall [2] studied the absorption spectrum of tetravalent uranium in $\mathrm{DClO}_{4}$ solution between 200 and $2600 \mathrm{~nm}$. Carnall and co-workers [3] studied the crystal-field spectra of $\mathrm{UF}_{4}$, including all the excited states except ${ }^{1} \mathrm{~S}_{0}$. There is \footnotetext{
992.

E-mail address: Koen.Binnemans@chem.kuleuven.ac.be (K. Binnemans)
}

*Corresponding author. Tel.: +32-0-16-327-446; fax: +32-0-16-327- a very close correlation with the band structure observed for $\mathrm{U}^{4+}$ in water. Free-ion and crystal-field parameters were determined by fitting the calculated energy levels to the experimental energy levels. Krupa [4] reviewed the spectroscopic properties of the tetravalent actinide ions in crystalline solids. The intensities of the transitions of actinides are reviewed by Görller-Walrand and Binnemans [5]. Spectroscopic studies of $\mathrm{U}^{4+}$ in glasses are sparse. Aliaga et al. [6] recorded the absorption spectra of tetravalent uranium in the fluorozirconate glass $55 \mathrm{ZrF}_{4}$ $30 \mathrm{BaF}_{2}-15 \mathrm{UF}_{4}$. In this glass, $\mathrm{UF}_{4}$ is a glass-former. The peaks were assigned according to the work of Conway on $\mathrm{UF}_{4}$ in $\mathrm{CaF}_{2}$ [1]. Thin samples show in transmission a green colour, which is characteristic for the $\mathrm{U}^{4+}$ ion. However, a red colour was observed for thick samples in transmission. This is because all the wavelengths are largely absorbed, except the red part of the spectrum. Damarupani et al. [7] published spectroscopic data of $\mathrm{U}^{4+}$ in the fluorozirconate glass $48 \mathrm{ZrF}_{4}-23 \mathrm{BaF}_{2}-8 \mathrm{AlF}_{3}-$ $10 \mathrm{NaF}-10 \mathrm{LiF}-1 \mathrm{UF}_{4}$.

In this paper, we present a spectroscopic study of the tetravalent uranium ion in fluoride, fluorophosphate and in phosphate glasses. We selected these types of matrices, because the spectral properties of the trivalent lanthanide ions have been widely studied in glasses with similar compositions [5]. Absorption and magnetic circular dichroism (MCD) spectra were recorded. The aim of this study is to compare the spectral behaviour of $\mathrm{U}^{4+}$ in different 
non-crystalline matrices and to compare the results with other $\mathrm{U}^{4+}$ systems. The experimental energy levels of the $5 \mathrm{f}^{2}$ electronic configuration of $\mathrm{U}^{4+}$ are used to determine a set of free-ion parameters. With these free-ion parameters it is possible to calculate the composition of the wavefunctions of the free-ion levels. The spin-orbit coupling parameter is used to compare the spectroscopic properties of $\mathrm{U}^{4+}$ in different matrices. The characteristics of the $5 \mathrm{f}^{2}$ electronic configuration of tetravalent uranium are somewhat similar to the $4 \mathrm{f}^{2}$ electronic configuration of trivalent praseodymium, since both $\mathrm{U}^{4+}$ and $\operatorname{Pr}^{3+}$ have the same number of electrons in their f-shell.

\section{Experimental details}

The following glasses were synthesised: the fluoride glasses $\quad 51.6 \mathrm{ZrF}_{4}-29.8 \mathrm{BaF}_{2}-4 \mathrm{LaF}_{3}-3 \mathrm{AlF}_{3}-11.5 \mathrm{NaF}-$ $0.1 \mathrm{UF}_{4} \quad\left(\mathrm{ZBLAN}: \mathrm{U}^{4+}\right), \quad 22.9 \mathrm{ZrF}_{4}-15 \mathrm{AlF}_{3}-10 \mathrm{YF}_{3}-$ $25 \mathrm{ZnF}_{2}-27 \mathrm{SrF}_{2}-0.1 \mathrm{UF}_{4}$, the fluorophosphate glasses $75 \mathrm{NaPO}_{3}-24.9 \mathrm{MgF}_{2}-0.1 \mathrm{UF}_{4}, \quad 75 \mathrm{NaPO}_{3}-24.5 \mathrm{CaF}_{2}-$ $0.5 \mathrm{UF}_{4}, 75 \mathrm{NaPO}_{3}-24.9 \mathrm{BaF}_{2}-0.1 \mathrm{UF}_{4}$ and the phosphate glass $75 \mathrm{NaPO}_{3}-24.9 \mathrm{ZnO}-0.1 \mathrm{UF}_{4}$. We chose these glass compositions, because of their good glass-forming abilities. The fluorophosphate glasses were prepared by melting the required amounts of sodium metaphosphate $\left(\mathrm{NaPO}_{3}\right)$ and the fluoride compounds in a platinum tube at a temperature of ca. $900^{\circ} \mathrm{C}$. After melting, heating was continued for $15 \mathrm{~min}$ to homogenise the melt. Then, the melt was cast in a brass mould (preheated to $250-300^{\circ} \mathrm{C}$ ). In order to remove strain, the glass samples were annealed for $4 \mathrm{~h}$ in a furnace at $270^{\circ} \mathrm{C}$. The phosphate glasses were prepared in a similar way. For the fluoride glasses, the oxides $\mathrm{ZrO}_{2}$ en $\mathrm{Al}_{2} \mathrm{O}_{3}$ were transformed first into the corresponding fluorides during a fluorination step with $\mathrm{NH}_{4} \mathrm{HF}_{2}$ [8], before melting the batch and casting the glass. Finally, the glass samples were cut and polished. All the glasses show a dark green colour, typical for the tetravalent uranium ion. Depending on the chemical compositions, differences in the colour tinge can be observed. Optical absorption spectra were recorded between 300 and $2600 \mathrm{~nm}$ on a Shimadzu UV-3100 spectrophotometer or an AVIV 17DS spectrophotometer. In general, a spectral bandwidth of $0.2 \mathrm{~nm}$ was used in the ultraviolet and visible spectral region, and a bandwidth of $1 \mathrm{~nm}$ in the nearinfrared. Spectra were recorded at ambient temperature. Magnetic circular dichroism (MCD) spectra were recorded on an AVIV 62DS circular dichroism spectrometer, equipped with an electromagnet. The magnetic field strength was approximately 9000 Gauss (0.9 Tesla).

\section{Theoretical analysis}

The positions of the absorption bands are used to determine the energetic position of the $5 \mathrm{f}^{2}$ configuration of the tetravalent uranium ion. The energy levels are parametrised in terms of a set of free-ion parameters, just as in the case of trivalent lanthanide ions doped into host single crystals [9]. The free-ion Hamiltonian is characterised by a set of three electron repulsion parameters $\left(F^{2}, F^{4}, F^{6}\right)$, by the spin-orbit coupling constant $\zeta_{5 f}$, the Trees configuration interaction parameters $(\alpha, \beta, \gamma)$, and parameters which describe magnetic interactions $\left(M^{0}, M^{2}, M^{4}, P^{2}, P^{4}\right.$, $\left.P^{6}\right)$. A further parameter $E_{\text {avg }}$ takes into account the kinetic energy of the electrons and their interactions with the nucleus. It shifts only the baricenter of the whole $5 \mathrm{f}$ configuration. So one can write [10,11]:

$$
\begin{aligned}
H_{\text {free-ion }}= & E_{\text {avg }}+\sum_{k} F^{k} f_{k}+\zeta_{5 f} A_{\text {SO }}+\alpha L(L+1) \\
& +\beta G\left(G_{2}\right)+\gamma G\left(R_{7}\right)+\sum_{k} P^{k} p_{k}+\sum_{l} M^{l} m_{l},
\end{aligned}
$$

where $k=2,4,6$ and $l=0,2,4$, whereas $f_{k}$ and $A_{s o}$ represent the angular part of the electrostatic and spinorbit interaction respectively. $L$ is the total orbital angular momentum. $G\left(G_{2}\right)$ and $G\left(R_{7}\right)$ are the Casimir operators for the groups $G_{2}$ and $R_{7}$. The $p_{k}$ and $m^{l}$ represent the operators for the magnetic corrections.

\section{Results and discussion}

In Fig. 1, the absorption spectra of a fluoride glass $\left(22.9 \mathrm{ZrF}_{4}-15 \mathrm{AlF}_{3}-10 \mathrm{YF}_{3}-25 \mathrm{ZnF}_{2}-27 \mathrm{SrF}_{2}-0.1 \mathrm{UF}_{4}\right)$, fluoro-phosphate glass $\left(75 \mathrm{NaPO}_{3}-24.9 \mathrm{BaF}_{2}-0.1 \mathrm{UF}_{4}\right)$ and a phosphate glass $\left(75 \mathrm{NaPO}_{3}-24.9 \mathrm{ZnO}-0.1 \mathrm{UF}_{4}\right)$ are shown. The spectra exhibit comparable features. First of all, the absorption bands are much broader than the absorption bands in the absorption spectra of trivalent lanthanide ions, but smaller than the absorption bands of $\mathrm{d}-\mathrm{d}$ transitions of transition metal ions. This broadening is due to a less efficient shielding of the 5f-shell from the environment by the closed $6 \mathrm{~s}^{2} 6 \mathrm{p}^{6}$ shell, in comparison with the shielding of the $4 \mathrm{f}$-shell by the closed $5 \mathrm{~s}^{2} 5 \mathrm{p}^{6}$ shell. Therefore, the crystal-field effect has a greater influence on the spectroscopic properties of the actinides than of the lanthanides. Because of the broad and overlapping bands, spectral assignments are more difficult than in the case of lanthanide spectra. No crystal-field fine structure could be observed in the spectra of the glasses. This is due to the inhomogeneous line-broadening in the glasses caused by the broad distribution of sites in the glass matrix. Secondly, all the spectra show an UV cut-off at $30000 \mathrm{~cm}^{-1}$. This cut-off is not only due to matrix absorption (as in the case of the phosphate and the fluorophosphate glasses), but also to the allowed, and thus intense $5 \mathrm{f}^{2} \rightarrow 5 \mathrm{f}^{1} 6 \mathrm{~d}^{1}$ transition. Thirdly, the most intense transition is the ${ }^{3} \mathrm{~F}_{3},{ }^{1} \mathrm{G}_{4} \leftarrow{ }^{3} \mathrm{H}_{4}$ transition in the near-infrared, around $9000 \mathrm{~cm}^{-1}$. The most obvious difference among the absorption spectra in the three glass samples is observed for the complex band in the spectral region 


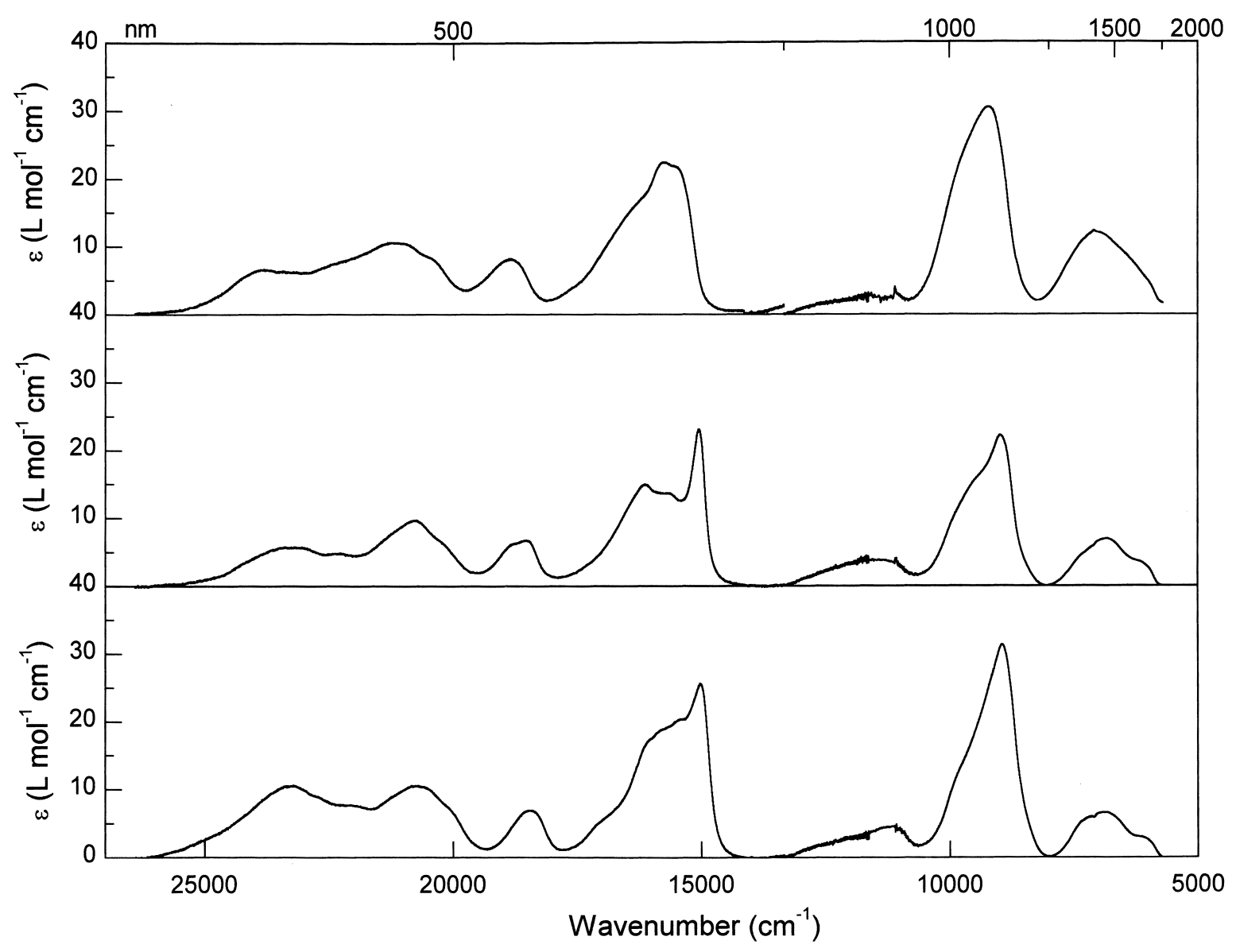

Fig. 1. Absorption spectra of glasses doped with tetravalent uranium at ambient temperature: the fluoride glass $22.9 \mathrm{ZrF}_{4}-15 \mathrm{AlF}_{3}-10 \mathrm{YF}_{3}-25 \mathrm{ZnF}_{2}-$ $27 \mathrm{SrF}_{2}-0.1 \mathrm{UF}_{4}$ (upper spectrum), the fluorophosphate glass $75 \mathrm{NaPO}_{3}-24.9 \mathrm{MgF}_{2}-0.1 \mathrm{UF}_{4}$ (middle spectrum) and the phosphate glass $75 \mathrm{NaPO}_{3}-24.9 \mathrm{ZnO}-$ $0.1 \mathrm{UF}_{4}$ (lower spectrum).

$14500-18000 \mathrm{~cm}^{-1}$. This band can be assigned to transitions of the ${ }^{3} \mathrm{H}_{4}$ ground state to the energy levels ${ }^{3} \mathrm{~F}_{4},{ }^{1} \mathrm{D}_{2}$ and ${ }^{3} \mathrm{P}_{0}$. These spectral differences are due to the combined effect of the differences in the magnitude of the spin-orbit coupling, the crystal-field strength and the inhomogeneous line-broadening. Differences in intensities are observed for the transitions in the glasses, depending on the chemical nature of the glass, but it is not easy to relate these differences to the glass composition. This is possibly due to the low doping concentration of the glasses (0.1 $\left.\mathrm{mol} \% \mathrm{UF}_{4}\right)$, so that small errors in the doping concentration have a large influence on the molar absorptivities. The order in intensities for the lanthanide ions is fluoride glasses $<$ fluorophosphate glasses $<$ phosphate glasses [12]. We could not decide whether this order is also followed by the uranium glasses. Because the $\mathrm{U}^{4+}$ ion is a hard acid and the fluoride ions and the oxygen atoms in the phosphate group are hard bases, it can be assumed that the uranium ions in fluorophosphate glasses have mixed coordination by fluoride ions and phosphate groups, so that the spectral behaviour of fluorophosphate glasses is close to that of fluoride and phosphate glasses.

Reports on magnetic circular dichroism spectra (MCD) of tetravalent actinide ions are very sparse in the literature. Mackey et al. [13] recorded the MCD spectrum of $\mathrm{ZrSiO}_{4}: \mathrm{U}^{4+}$. The authors found that most of the observed MCD signals had the shape of an A-term (derivative of an absorption band) [14].

They used the $A$-term MCD signals to calculate the $g$ values of the energy levels. The room temperature MCD and absorption spectrum of the $75 \mathrm{NaPO}_{3}-24.5 \mathrm{CaF}_{2}-$ $0.5 \mathrm{UF}_{4}$ glass is shown in Fig. 2. The MCD spectrum is dominated by an intense $A$-term, which can be assigned to the $\left({ }^{3} \mathrm{~F}_{4}+{ }^{1} \mathrm{D}_{2}+{ }^{3} \mathrm{P}_{0}\right) \leftarrow{ }^{3} \mathrm{H}_{4}$ transition at $16100 \mathrm{~cm}^{-1}$. The $A$-term has a positive sign, which means that the positive lobe is at the high energy side. The other transitions give MCD signals which don't have the shape of a derivative of an absorption band, but which are very hard to interpret. Therefore, we can conclude that the MCD spectrum of the $\mathrm{U}^{4+}$ ion in a glass matrix does not give additional information in comparison with the absorption spectrum. This is in contrast to the MCD signals of the fine line transitions of $\mathrm{U}^{4+}$ in a crystalline matrix [13].

In Table 1, the experimental and calculated baricenters of the free-ion levels in the fluorophosphate glass $75 \mathrm{NaPO}_{3}-24.9 \mathrm{MgF}_{2}-0.1 \mathrm{UF}_{4}$ are listed. The ground state 


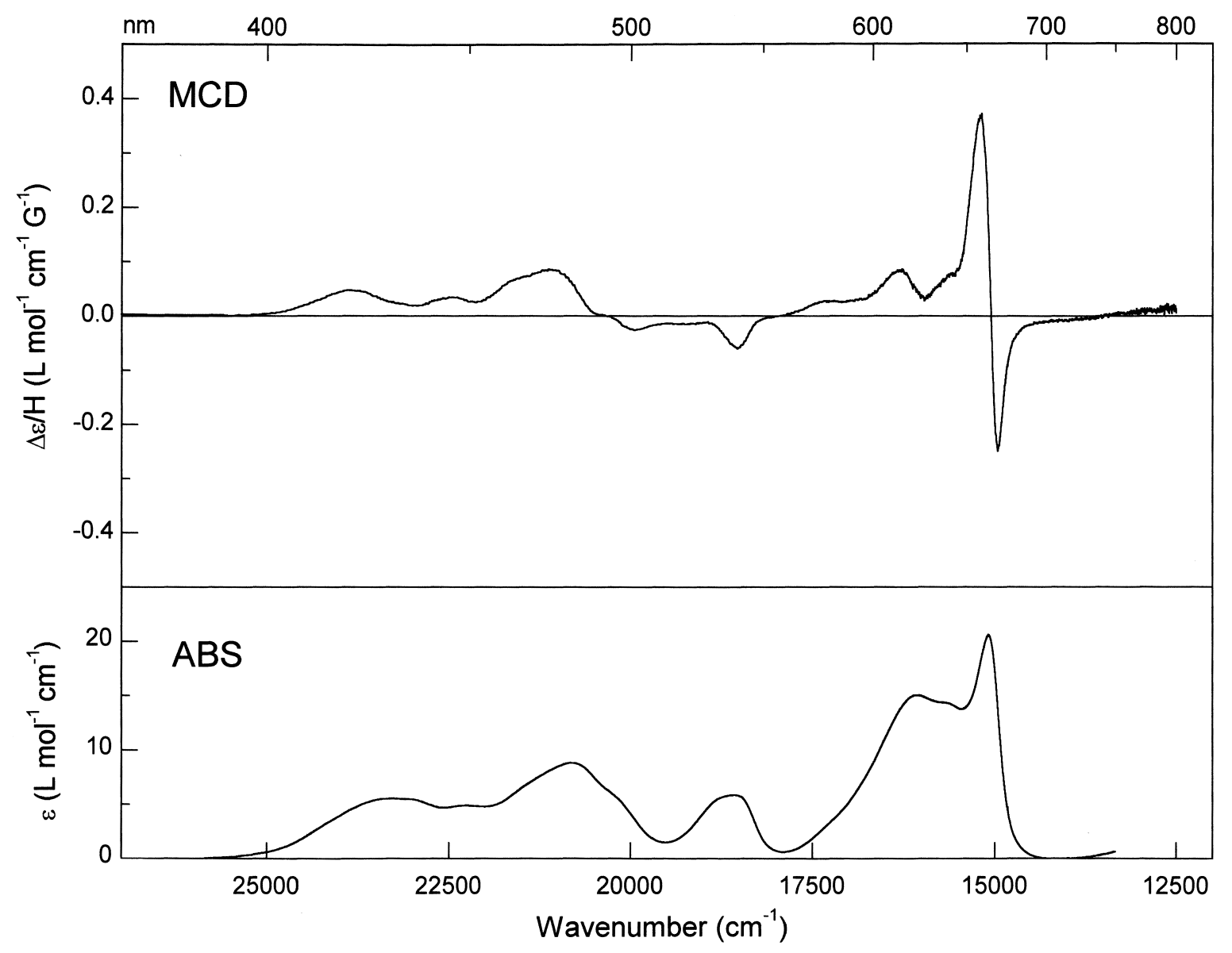

Fig. 2. : Absorption and $\mathrm{MCD}$ spectrum of the fluorophosphate glass $75 \mathrm{NaPO}_{3}-24.5 \mathrm{CaF}_{2}-0.5 \mathrm{UF}_{4}$ at room temperature.

is ${ }^{3} \mathrm{H}_{4}$. Of the 13 free-ion levels, only the ${ }^{3} \mathrm{~F}_{2},{ }^{3} \mathrm{H}_{5},{ }^{3} \mathrm{H}_{6}$ and ${ }^{3} \mathrm{P}_{1}$ levels do not overlap with other free-ion levels. Although there is an overlap of the ${ }^{3} \mathrm{P}_{2}$ and ${ }^{1} \mathrm{I}_{6}$ levels, their experimental positions could be determined. Because it is impossible to determine the baricenters of the levels ${ }^{3} \mathrm{~F}_{3}$,

Table 1

Experimental $\left(E_{\text {exp }}\right)$ and calculated energy levels $\left(E_{\text {calc }}\right)$ of tetravalent uranium in the fluorophosphate glass $75 \mathrm{NaPO}_{3}-24.9 \mathrm{MgF}_{2}-0.1 \mathrm{UF}_{4}{ }^{(\text {a) }}$

\begin{tabular}{llc}
\hline${ }^{2 \mathrm{~S}+1} \mathrm{~L}_{\mathrm{J}}{ }^{(\mathrm{b})}$ & $E_{\text {exp }}\left(\mathrm{cm}^{-1}\right)$ & $E_{\text {calc }}\left(\mathrm{cm}^{-1}\right)$ \\
\hline${ }^{3} \mathrm{H}_{4}$ & - & 548 \\
${ }^{3} \mathrm{~F}_{2}$ & 4788 & 4842 \\
${ }^{3} \mathrm{H}_{5}$ & 6891 & 6757 \\
${ }^{1} \mathrm{G}_{4}$ & - & 8796 \\
${ }^{3} \mathrm{~F}_{3}$ & - & 9291 \\
${ }^{3} \mathrm{H}_{6}$ & 11756 & 11862 \\
${ }^{3} \mathrm{~F}_{4}$ & - & 15698 \\
${ }^{1} \mathrm{D}_{2}$ & - & 16243 \\
${ }^{3} \mathrm{P}_{0}$ & - & 16400 \\
${ }^{3} \mathrm{P}_{1}$ & 18740 & 18741 \\
${ }^{1} \mathrm{I}_{6}$ & 20840 & 20832 \\
${ }^{3} \mathrm{P}_{2}$ & 23152 & 23134 \\
${ }^{1} \mathrm{~S}_{0}$ & - & 36336 \\
\hline
\end{tabular}

\footnotetext{
${ }^{\mathrm{a}}$ The free-ion parameters used for the calculation of the energy levels are listed in Table 2;

${ }^{\mathrm{b}}$ Only the largest ${ }^{2 \mathrm{~S}+1} \mathrm{~L}_{\mathrm{J}}$ contribution to the wavefunction is listed.
}

${ }^{3} \mathrm{~F}_{4},{ }^{1} \mathrm{G}_{4},{ }^{1} \mathrm{D}_{2}$ and ${ }^{3} \mathrm{P}_{0}$ with a sufficient accuracy, these levels were not used for the determination of the free-ion parameters. The ground state ${ }^{3} \mathrm{H}_{4}$ was not used in the fitting procedure, because the baricenter could not be determined due to the absence of sufficient information on the splitting of this level by the crystal field perturbation. Although the energetic position of lowest crystal-field of the ${ }^{3} \mathrm{H}_{4}$ level is $0 \mathrm{~cm}^{-1}$, this is not true for the baricenter. For instance, the baricenter of the ${ }^{3} \mathrm{H}_{4}$ state in $\mathrm{UF}_{4}$ is $945.5 \mathrm{~cm}^{-1}$ [3]. The ${ }^{1} \mathrm{~S}_{0}$ level could not be observed in any of the glasses. We used the free-ion parameters of $\mathrm{UF}_{4}$ reported by Carnall et al. [3] as the starting set to optimise the parameters $E_{\text {avg }}, F^{2}, F^{4}, F^{6}$ and $\zeta_{5 \mathrm{f}}$. The other free-ion parameters were constrained during the fitting procedure. For the other glasses, comparable results are found. The free-ion parameters for the $\mathrm{U}^{4+}$-doped glasses are listed in Table 2. The wavefunctions of the $5 \mathrm{f}^{2}$ configuration of $\mathrm{U}^{4+}$ in $75 \mathrm{NaPO}_{3}-24.9 \mathrm{MgF}_{2}-0.1 \mathrm{UF}_{4}$ are given in Table 3 . The wavefunctions have been calculated in the intermediate coupling scheme, which means that $J$ remains a good quantum number (but not $S$ and $L$ ). In the intermediate coupling scheme, the wavefunction of each freeion level is a linear combination of contributions from levels with the same $J$ quantum number. For instance, the 
Table 2

Free-ion parameters (in $\mathrm{cm}^{-1}$ ) of tetravalent uranium in glasses ${ }^{\text {(a) }}$

\begin{tabular}{|c|c|c|c|c|c|c|}
\hline Parameter & Glass $A^{(b)}$ & Glass B & Glass C & Glass D & Glass E & Glass F \\
\hline$E_{\text {avg }}$ & 12184 & 12306 & 12295 & 12546 & 12499 & 12116 \\
\hline$F^{2}$ & 48156 & 47032 & 47003 & 47972 & 48444 & 49296 \\
\hline$F^{4}$ & 18346 & 24011 & 24546 & 22281 & 24539 & 11742 \\
\hline$F^{6}$ & 20562 & 21318 & 21115 & 21999 & 22482 & 21550 \\
\hline$\alpha$ & (34.74) & (34.74) & (34.74) & (34.74) & (34.74) & (34.74) \\
\hline$\beta$ & $(-767.3)$ & $(-767.3)$ & $(-767.3)$ & $(-767.3)$ & $(-767.3)$ & $(-767.3)$ \\
\hline$\gamma$ & (913.9) & (913.9) & (913.9) & (913.9) & (913.9) & (913.9) \\
\hline$\zeta_{5 \mathrm{f}}$ & 1891 & 1842 & 1874 & 1962 & 1928 & 1746 \\
\hline$M_{\text {tot }}$ & $(0.775)$ & $(0.775)$ & $(0.775)$ & $(0.775)$ & $(0.775)$ & $(0.775)$ \\
\hline$P_{\mathrm{tot}}$ & (2715) & (2715) & (2715) & (2715) & (2715) & (2715) \\
\hline$\sigma$ & 86 & 80 & 87 & 51 & 87 & 18 \\
\hline
\end{tabular}

${ }^{a}$ The values in brackets were taken from Ref. [3] and were constrained during the fitting procedure.

${ }^{\mathrm{b}}$ Glass compositions: Glass A: $75 \mathrm{NaPO}_{3}-24.9 \mathrm{BaF}_{2}-0.1 \mathrm{UF}_{4}$, Glass B: $75 \mathrm{NaPO}_{3}-24.9 \mathrm{MgF}_{2}-0.1 \mathrm{UF}_{4}, \mathrm{Glass}_{\mathrm{C}} \mathrm{C}$ 75NaPO $3-24.5 \mathrm{CaF}_{2}-0.5 \mathrm{UF}_{4}$, Glass $\mathrm{D}_{3}$ : $52.9 \mathrm{ZrF}_{4}-30 \mathrm{BaF}_{2}-4 \mathrm{LaF}_{3}-3 \mathrm{AlF}_{3}-10 \mathrm{NaF}-0.1 \mathrm{UF}_{4}\left(\mathrm{ZBLAN}: \mathrm{U}^{4+}\right)$, Glass E: $22.9 \mathrm{ZrF}_{4}-15 \mathrm{AlF}_{3}-10 \mathrm{YF}_{3}-25 \mathrm{ZnF}_{2}-27 \mathrm{SrF}_{2}-0.1 \mathrm{UF}_{4}, \mathrm{Glass}^{\mathrm{F}}$ : $75 \mathrm{NaPO}_{3}-$ $24.9 \mathrm{ZnO}-0.1 \mathrm{UF}_{4}$

ground state ' $3 \mathrm{H}_{4}$ ' is not a pure ${ }^{3} \mathrm{H}_{4}$ state, but also contains contributions from the ${ }^{1} \mathrm{G}_{4}$ and ${ }^{3} \mathrm{~F}_{4}$ states $(J=4)$. In fact the wavefunction of the ${ }^{\text {' }} \mathrm{H}_{4}$ ' state is $85 \%{ }^{3} \mathrm{H}_{4}+$ $14 \%{ }^{1} \mathrm{G}_{4}+1 \%{ }^{3} \mathrm{~F}_{4}$. It is common practice to label a free-ion level by the ${ }^{2 S+1} L_{J}$ state which has the largest contribution to a particular free-ion level. Only in the case that within a particular electronic configuration there is only one state with a given $J$ quantum number, the state can be described well within the Russell-Saunders coupling scheme (both $S, L$ an $J$ are good quantum numbers). For instance, in the $5 \mathrm{f}^{2}$ electronic configuration the level ${ }^{3} \mathrm{H}_{5}$ ' is for $100 \%$ pure ${ }^{3} \mathrm{H}_{5}$, because in the $5 \mathrm{f}^{2}$ configuration there is only one state with $J=5$. For the same reason, also the states ${ }^{~}{ }^{3} \mathrm{~F}_{3}$ ' and ${ }^{6} \mathrm{P}_{1}$ are $100 \%{ }^{3} \mathrm{~F}_{3}$ and ${ }^{3} \mathrm{P}_{1}$ respectively. The crystal-field perturbation can cause $J$ mixing, so that contributions of states ${ }^{2 \mathrm{~S}+1} L_{J}$ with a different $J$-value can contribute to the wavefunction of a state. We do not include $J$-mixing in our calculations, because no visible evidence of crystal-field splitting is

\section{Table 3}

Wavefunctions of the $5 \mathrm{f}^{2}$ electronic configuration of tetravalent uranium in the fluorophosphate glass $75 \mathrm{NaPO}_{3}-24.9 \mathrm{MgF}_{2}-0.1 \mathrm{UF}_{4}$, calculated in the intermediate coupling scheme ${ }^{\mathrm{a}}$

\begin{tabular}{|c|c|}
\hline${ }^{2}{ }^{2 \mathrm{~S}+1} \mathrm{~L}_{\mathrm{J}}{ }^{\prime}$ & Wavefunction components \\
\hline${ }^{3} \mathrm{H}_{4}{ }^{\prime}$ & $85 \%{ }^{3} \mathrm{H}_{4}+14 \%{ }^{1} \mathrm{G}_{4}+1 \%{ }^{3} \mathrm{~F}_{4}$ \\
\hline${ }^{3} \mathrm{~F}_{2}$, & $87 \%{ }^{3} \mathrm{~F}_{2}+12 \%{ }^{1} \mathrm{D}_{2}+1 \%{ }^{3} \mathrm{P}_{2}$ \\
\hline${ }^{3} \mathrm{H}_{5}{ }^{\prime}$ & $100 \%{ }^{3} \mathrm{H}_{5}$ \\
\hline${ }^{1} \mathrm{G}_{4}$, & $50 \%{ }^{1} \mathrm{G}_{4}+37 \%{ }^{3} \mathrm{~F}_{4}+13 \%{ }^{3} \mathrm{H}_{4}$ \\
\hline${ }^{3} \mathrm{~F}_{3}$, & $100 \%{ }^{3} \mathrm{~F}_{3}$ \\
\hline${ }^{3} \mathrm{H}_{6}^{3}$, & $93 \%{ }^{3} \mathrm{H}_{6}+7 \%{ }^{1} \mathrm{I}_{6}$ \\
\hline${ }^{3} \mathrm{~F}_{4}^{6}$, & $62 \%{ }^{3} \mathrm{~F}_{4}+36 \%{ }^{1} \mathrm{G}_{4}+2 \%{ }^{3} \mathrm{H}_{4}$ \\
\hline${ }^{1} \mathrm{D}_{2}$, & $51 \%{ }^{1} \mathrm{D}_{2}+39 \%{ }^{3} \mathrm{P}_{2}+10 \%{ }^{3} \mathrm{~F}_{2}$ \\
\hline${ }^{3} \mathrm{P}_{0}{ }^{\prime}$ & $92 \%{ }^{3} \mathrm{P}_{0}+8 \%{ }^{1} \mathrm{~S}_{0}$ \\
\hline${ }^{3} \mathrm{P}_{1}$, & $100 \%{ }^{3} \mathrm{P}_{1}$ \\
\hline${ }^{1} \mathrm{I}_{6}$, & $93 \%{ }^{1} \mathrm{I}_{6}+7 \%{ }^{3} \mathrm{H}_{6}$ \\
\hline${ }^{3} \mathrm{P}_{2}$, & $60 \%{ }^{3} \mathrm{P}_{2}+37 \%{ }^{1} \mathrm{D}_{2}+3 \%{ }^{3} \mathrm{~F}_{2}$ \\
\hline & $92 \%{ }^{1} \mathrm{~S}_{0}+8 \%{ }^{3} \mathrm{P}_{0}$ \\
\hline
\end{tabular}

${ }^{\mathrm{a}}$ The free-ion parameters used to calculate the wavefunctions are listed in Table 2. found in the glass matrices. For some free-ion levels, it is difficult to label them by a single ${ }^{2 \mathrm{~S}+1} L_{J}^{\prime}$ label, because several ${ }^{2 \mathrm{~S}+1} L_{J}$ terms have a comparable contribution to the total wavefunction. The $\zeta_{5 \mathrm{f}}$ values of the phosphate and the fluorophosphate glasses are comparable with the values of this parameter for $\mathrm{U}^{4+}$ in crystalline host matrices (see Table 4). However the $\zeta_{5 f}$ values for the $\mathrm{U}^{4+}$ ion in the two fluoride glasses are significant larger. Thus, the $\zeta_{5 \mathrm{f}}$ values increase in the order phosphate glasses $<$ fluorophosphate glasses $<$ fluoride glasses.

In order to compare the $5 \mathrm{f}^{2}$ configuration of $\mathrm{U}^{4+}$ and the $4 \mathrm{f}^{2}$ configuration of $\operatorname{Pr}^{3+}$, we compared the spectra of the fluorozirconate glasses ZBLAN: $\mathrm{U}^{4+}$ and ZBLAN:Pr ${ }^{3+}$. Both glasses are green, but the $\operatorname{Pr}^{3+}$ glass shows a more yellow-green colour $[15,16]$. The intensities are higher and the absorption bands are broader in the ZBLAN: $\mathrm{U}^{4+}$ glass than in the ZBLAN: $\operatorname{Pr}^{3+}$ glass. In Table 5 the free-ion parameters for $\mathrm{U}^{4+}$ and $\mathrm{Pr}^{3+}$ in the ZBLAN matrix are given. The $F^{k}$ electron repulsion parameters have lower values in ZBLAN: $\mathrm{U}^{4+}$ than in ZBLAN:Pr ${ }^{3+}$, but the spin-orbit coupling parameter is much larger for ZBLAN:U $\mathrm{U}^{4+}\left(1962 \mathrm{~cm}^{-1}\right)$ than for ZBLAN: $\mathrm{Pr}^{3+}$ (727 $\mathrm{cm}^{-1}$ ). Although the other free-ion parameters of the two systems also differ, these parameters incorporate minor perturbations and do not greatly influence the position of the energy levels. As a result of the differences in the free-ion parameters the relative position of some of the free-ion energy levels is different in the $5 f^{2}$ and the $4 f^{2}$ configurations. For instance, in the $4 \mathrm{f}^{2}$ configuration of $\mathrm{Pr}^{3+}$, the ${ }^{3} \mathrm{H}_{J}$ levels $(J=4,5,6)$ are well separated from the ${ }^{3} \mathrm{~F}_{J}$ levels $(J=2,3,4)$, whereas the ${ }^{3} \mathrm{H}_{J}$ and ${ }^{3} \mathrm{~F}_{J}$ levels overlap in the $5 \mathrm{f}^{2}$ configuration of $\mathrm{U}^{4+}$. For the lanthanides, it is possible to introduce gradually the perturbations which remove the degenerations of the $4 \mathrm{f}^{\mathrm{n}}$ configuration: central field approximation $\rightarrow$ electron repulsion $\rightarrow$ spin-orbit coupling $\rightarrow$ crystal-field interaction. For the $5 \mathrm{f}^{\mathrm{n}}$ configurations of the actinides, this is no longer possible, because the order of magnitude of the interac- 
Table 4

Comparison of the spin-orbit coupling parameter $\zeta_{5 \mathrm{f}}$ for tetravalent uranium ion in different matrices

\begin{tabular}{|c|c|c|}
\hline Matrix & $\zeta_{5 \mathrm{f}}\left(\mathrm{cm}^{-1}\right)$ & Reference \\
\hline $\mathrm{UF}_{4}$ & 1761 & [3] \\
\hline $\mathrm{ThBr}_{4}: \mathrm{U}^{4+}$ & 1783 & {$[18]$} \\
\hline $\mathrm{Cs}_{2} \mathrm{UCl}_{6}$ & 1792 & [19] \\
\hline $\mathrm{UCl}_{4}$ & 1805 & {$[20]$} \\
\hline $\mathrm{ThCl}_{4}: \mathrm{U}^{4+}$ & 1808 & {$[21]$} \\
\hline $\mathrm{ThSiO}_{4}: \mathrm{U}^{4+}$ & 1840 & {$[23]$} \\
\hline $75 \mathrm{NaPO}_{3}-24.9 \mathrm{MgF}_{2}-0.1 \mathrm{UF}_{4}$ glass & 1842 & This work \\
\hline $75 \mathrm{NaPO}_{3}-24.5 \mathrm{CaF}_{2}-0.5 \mathrm{UF}_{4}$ glass & 1874 & This work \\
\hline $\mathrm{CaF}_{2}: \mathrm{U}^{4+}$ & 1870 & [1] \\
\hline $75 \mathrm{NaPO}_{3}-24.9 \mathrm{BaF}_{2}-0.1 \mathrm{UF}_{4}$ glass & 1891 & This work \\
\hline $22.9 \mathrm{ZrF}_{4}-15 \mathrm{AlF}_{3}-10 \mathrm{YF}_{3}-25 \mathrm{ZnF}_{2}-27 \mathrm{SrF}_{2}-0.1 \mathrm{UF}_{4}$ glass & 1928 & This work \\
\hline
\end{tabular}

tions is very much the same. A consequence of the much stronger spin-orbit coupling of the $5 \mathrm{f}^{2}$ configuration in comparison to the $4 \mathrm{f}^{2}$ configuration is that the deviation from the Russell-Saunders coupling scheme is more important for the $5 \mathrm{f}^{2}$ configuration than for the $4 \mathrm{f}^{2}$ configuration. For example the wavefunction of the ${ }^{3} \mathrm{P}_{0}$ ' state of $\operatorname{Pr}^{3+}$ is $99 \%{ }^{3} \mathrm{P}_{0}+1 \%{ }^{1} \mathrm{~S}_{0}$, whereas the wavefunction for the same state of $\mathrm{U}^{4+}$ is $92 \%{ }^{3} \mathrm{P}_{0}+8 \%{ }^{1} \mathrm{~S}_{0}$. The conclusions with respect to the behaviour of $\mathrm{U}^{4+}$ and $\operatorname{Pr}^{3+}$ in the other matrices are analogous.

\section{Conclusions}

In conclusion, we can state that although tetravalent uranium and trivalent praseodymium ions have comparable electronic configurations $\left(5 \mathrm{f}^{2}\right.$ for $\mathrm{U}^{4+}$ and $4 \mathrm{f}^{2}$ for $\mathrm{Pr}^{3+}$ ) and although their spectroscopic behaviour shows some similarities (for instance both ions give a green colour to the glasses), differences in the absorption spectra can be

Table 5

Comparison of the free-ion parameters of ZBLAN: $\mathrm{U}^{4+}$ and ZBLAN: $\mathrm{Pr}^{3+}$

\begin{tabular}{|c|c|c|}
\hline Parameter & $\begin{array}{l}\text { Value }\left(\mathrm{cm}^{-1}\right) \text { in } \\
\text { ZBLAN: } \mathrm{U}^{4+}\end{array}$ & $\begin{array}{l}\text { Value }\left(\mathrm{cm}^{-1}\right) \text { in } \\
\text { ZBLAN:Pr }\end{array}$ \\
\hline$E_{\text {avg }}$ & 12546 & 10058 \\
\hline$F^{2}$ & 47972 & 69023 \\
\hline$F^{4}$ & 22281 & 50768 \\
\hline$F^{6}$ & 21999 & 32910 \\
\hline$\alpha$ & (34.74) & (16.32) \\
\hline$\beta$ & $(-767.3)$ & $(-566.6)$ \\
\hline$\gamma$ & (913.9) & (1371) \\
\hline$\zeta_{5 f}$ & 1962 & 726 \\
\hline$M^{0}$ & $(0.775)$ & $(2.08)$ \\
\hline$M^{2}$ & $0.56 M^{0}$ & $0.56 M^{0}$ \\
\hline$M^{4}$ & $0.38 M^{0}$ & $0.38 M^{0}$ \\
\hline$P^{2}$ & $(2715)$ & $(-88.6)$ \\
\hline$P^{4}$ & $0.5 P^{2}$ & $0.5 P^{2}$ \\
\hline$P^{6}$ & $0.1 P^{2}$ & $0.1 P^{2}$ \\
\hline
\end{tabular}

observed. The most obvious differences are broader and more intense absorption bands in the $\mathrm{U}^{4+}$ spectrum than in the $\operatorname{Pr}^{3+}$ spectrum. The spin-orbit interaction is much stronger for $\mathrm{U}^{4+}$, resulting in an increased mixing of the wavefunctions (larger deviation from the Russell-Saunders coupling scheme). The absorption spectra of fluoride, fluorophosphate and phosphate glasses have the same appearance, but a closer look reveals differences in the fine structure and intensities of the spectra. Sets of free-ion parameters for the glasses doped with tetravalent uranium were determined.

\section{Acknowledgements}

$\mathrm{KB}$ is a Postdoctoral Fellow of the FWO-Flanders (Belgium). HDL thanks the FWO for financial support (FWO research grant G.0124.95). We wish to thank M.F. Reid (University of Canterbury, Christchurch, New Zealand) for the permission to use his computer programmes.

\section{References}

[1] J.G. Conway, J. Chem. Phys. 31 (1959) 1002.

[2] D. Cohen, W.T. Carnall, J. Phys. Chem. 64 (1960) 1933.

[3] W.T. Carnall, G.K. Liu, C.W. Williams, M.F. Reid, J. Chem. Phys. 95 (1991) 7194.

[4] J.C. Krupa, Inorg. Chim. Acta. 139 (1987) 223.

[5] C. Görller-Walrand, K. Binnemans, in: K.A. Gschneidner jr, L. Eyring (Eds.), Handbook On the Physics and Chemistry of Rare Earths, Vol. 25, North-Holland, Amsterdam, 1998, p. 101, Chapter 167.

[6] N. Aliaga, G. Fonteneau, J. Lucas, Ann. Chim. Fr. 3 (1978) 51.

[7] V.D. Damarupani, S. Buddhudu, Y. Subramanyam, L.R. Moorthy, D.C. Hussain Sa, Czechoslovak J. Phys. 41 (1991) 85.

[8] M. Poulain, J. Lucas, Verres Refract. 32 (1978) 505.

[9] C. Görller-Walrand, K. Binnemans, in: K.A. Gschneidner jr, L. Eyring (Eds.), Handbook On the Physics and Chemistry of Rare 
Earths, Vol. 23, North-Holland, Amsterdam, 1996, p. 121, Chapter 155.

[10] B.G. Wybourne, Spectroscopic Properties of Rare Earths, Interscience, New York, 1965.

[11] H.M. Crosswhite, H. Crosswhite, J. Opt. Soc. Am. B. 1 (1984) 246.

[12] K. Binnemans, R. Van Deun, C. Görller-Walrand, J.L. Adam, J. Alloys Compds. 275/277 (1998) 455.

[13] D.J. Mackey, W.A. Runciman, E.R. Vance, Phys. Rev. B. 11 (1975) 211.

[14] P.J. Stephens, J. Chem. Phys. 52 (1970) 3489.

[15] K. Binnemans, C. Görller-Walrand, Chem. Phys. Lett. 235 (1995) 163.

[16] K. Binnemans, D. Verboven, C. Görller-Walrand, J. Lucas, N. Duhamel-Henry, J.L. Adam, J. Alloys Compds. 250 (1997) 321.
[17] G. Folcher, H. Marquet-Ellis, P. Rigny, E. Soulié, G. Goodman, J. Inorg. Nucl. Chem. 38 (1976) 747.

[18] P. Delamoye, K. Rajnak, M. Genet, N. Edelstein, Phys. Rev. B. 28 (1963) 4923.

[19] R.A. Satten, C.L. Schreiber, E.Y. Wong, J. Chem. Phys. 78 (1983) 79.

[20] C. Khan Malek, J.C. Krupa, M. Genet, Spectrochim. Acta A. 42 (1986) 907.

[21] C. Khan Malek, J.C. Krupa, P. Delamoye, M. Genet, J. Phys. 47 (1986) 1761.

[22] F. Auzel, S. Hubert, P. Delamoye, J. Lumin. 26 (1982) 251.

[23] C. Khan Malek, J.C. Krupa, J. Chem. Phys. 84 (1986) 6584. 